\title{
SPATIOTEMPORAL DYNAMICS OF SURFACE WATER EXTENT FROM THREE DECADES OF SEASONALLY CONTINUOUS LANDSAT TIME SERIES AT SUBCONTINENTAL SCALE
}

\author{
M.G. Tulbure ${ }^{\text {a, } * \text {, M. Broich }}{ }^{\text {a }}$, Stephen V. Stehman ${ }^{\text {b }}$

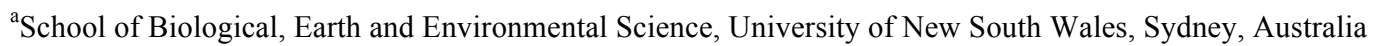 \\ ${ }^{\mathrm{b}}$ Department of Forest and Natural Resources Management, State University of New York, Syracuse, NY,USA \\ mirela.tulbure@unsw.edu.au
}

Commission TeS: VIII, WG VIII/4

KEY WORDS: Landsat time-series, seasonally continuous, surface water dynamics, flooding dynamics, Murray-Darling Basin, Australia, competing water demands, drought, random forest, long term trends, water, river basin, water management

\begin{abstract}
:
Surface water is a critical resource in semi-arid areas. The Murray-Darling Basin (MDB) of Australia, one of the largest semi-arid basins in the world is aiming to set a worldwide example of how to balance multiple interests (i.e. environment, agriculture and urban use), but has suffered significant water shrinkages during the Millennium Drought (1999-2009), followed by extensive flooding. Baseline information and systematic quantification of surface water (SW) extent and flooding dynamics in space and time are needed for managing SW resources across the basin but are currently lacking.

To synoptically quantify changes in SW extent and flooding dynamics over MDB, we used seasonally continuous Landsat TM and ETM+ data (1986 - 2011) and generic machine learning algorithms. We further mapped flooded forest at a riparian forest site that experienced severe tree dieback due to changes in flooding regime. We used a stratified sampling design to assess the accuracy of the SW product across time.

Accuracy assessment yielded an overall classification accuracy of $99.94 \%$, with producer's and user's accuracy of SW of $85.4 \%$ and $97.3 \%$, respectively. Overall accuracy was the same for Landsat 5 and 7 data but user's and producer's accuracy of water were higher for Landsat 7 than 5 data and stable over time.

Our validated results document a rapid loss in SW bodies. The number, size, and total area of SW showed high seasonal variability with highest numbers in winter and lowest numbers in summer. SW extent per season per year showed high interannual and seasonal variability, with low seasonal variability during the Millennium Drought.

Examples of current uses of the new dataset will be presented and include (1) assessing ecosystem response to flooding with implications for environmental water releases, one of the largest investment in environment in Australia; (2) quantifying drivers of SW dynamics (e.g. climate, human activity); (3) quantifying changes in SW dynamics and connectivity for water dependent organisms; (4) assessing the impact of flooding on riparian vegetation health. The approach developed here is globally applicable, relevant to areas with competing water demands (e.g. Okavango River delta, Mekong River Basin). Future work should incorporate Landsat 8 and Sentinel-2 data for continued quantification of SW dynamics.
\end{abstract}

\section{MANUSCRIPT}

Surface water is a critical resource in semi-arid areas. The Murray-Darling Basin (MDB) of Australia, one of the largest semi-arid basins in the world is aiming to set a worldwide example of how to balance multiple interests (i.e. environment, agriculture and urban use), but has suffered significant water shrinkages during the Millennium Drought (1999-2009), followed by extensive flooding. Baseline information and systematic quantification of surface water (SW) extent and flooding dynamics in space and time are needed for managing SW resources across the basin but are currently lacking.
To synoptically quantify changes in SW extent and flooding dynamics over MDB, we used seasonally continuous Landsat TM and ETM+ data (1986 - 2011) and generic machine learning algorithms. We further mapped flooded forest at a riparian forest site that experienced severe tree dieback due to changes in flooding regime. We used a stratified sampling design to assess the accuracy of the SW product across time.

Accuracy assessment yielded an overall classification accuracy of $99.94 \%$, with producer's and user's accuracy of SW of $85.4 \%$ and $97.3 \%$, respectively. Overall accuracy was the same for Landsat 5 and 7 data but user's and producer's accuracy of water were higher for Landsat 7 than 5 data and stable over

* Corresponding author 
time.

Our validated results document a rapid loss in SW bodies. The number, size, and total area of SW showed high seasonal variability with highest numbers in winter and lowest numbers in summer. SW extent per season per year showed high interannual and seasonal variability, with low seasonal variability during the Millennium Drought.

Examples of current uses of the new dataset will be presented and include (1) assessing ecosystem response to flooding with implications for environmental water releases, one of the largest investment in environment in Australia; (2) quantifying drivers of SW dynamics (e.g. climate, human activity); (3) quantifying changes in SW dynamics and connectivity for water dependent organisms; (4) assessing the impact of flooding on riparian vegetation health. The approach developed here is globally applicable, relevant to areas with competing water demands (e.g. Okavango River delta, Mekong River Basin). Future work should incorporate Landsat 8 and Sentinel-2 data for continued quantification of SW dynamics.

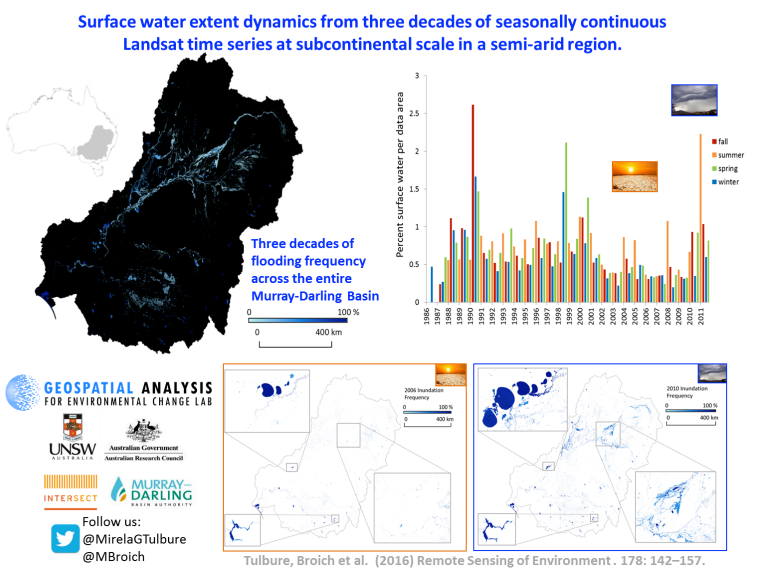

Figure 1. Surface water extent dynamics from three decades of seasonally continuous Landsat time series at subcontinental scale in a semi-arid region.

\section{REFERENCES}

Bishop-Taylor R., M.G. Tulbure, M. Broich. (2015). Surface water network structure, landscape resistance to movement and flooding vital for maintaining ecological connectivity across Australia's largest river basin. Landscape Ecology.

Broich M., A. Huete, M. Paget, X. Ma, R. Devadas, N. Restrepo-Coupe, K. Davies, A. Held. (2015). A spatially explicit Land Surface Phenology data product for science, monitoring and natural resources management applications. Environmental Modelling \& Software.

Broich M., A. Huete, M.G. Tulbure, X. Ma, Q. Xin, M. Paget, N. Restrepo-Coupe, K. Davies, R. Devadas, A. Held. Land surface phenological response to decadal climate variability across Australia using satellite remote sensing (2014). Biogeosciences Special Issue on Climate Extremes and Biogeochemical Cycles in the Terrestrial Biosphere: Impacts and Feedbacks Across Scales.
Heimhuber, V., M.G. Tulbure, M. Broich. (Accepted). Modelling 25 years of spatio-temporal surface water and inundation dynamics on large river basin scale using time series of earth observation data. Hydrology \& Earth System Sciences.

Tulbure, M. G., M. Broich, S.V. Stehman, A. Kommareddy. (2016). Surface water extent dynamics from three decades of seasonally continuous Landsat time series at subcontinental scale in a semi-arid region. Remote Sensing of Environment.

Tulbure, M.G., S. Kininmonth, M. Broich. (2014). Spatiotemporal dynamics of surface water networks across a global biodiversity hotspot - implications for conservation. Environmental Research Letters.

M.G. Tulbure and M. Broich. (2013). Spatiotemporal dynamic of surface water bodies using Landsat time-series data from 1999 to 2011. ISPRS Journal of Photogrammetry and Remote Sensing.

Shendryk, I., M. Broich, M.G. Tulbure, S.V. Alexandrov. (2016). Bottom-up delineation of individual trees from fullwaveform laser scans in a structurally complex eucalypt forest. Remote Sensing of Environment, 173, 69-83. 